\title{
ACONTECIMENTO E MEMÓRIA (2): ENCONTRO DE GÊNEROS DISCURSIVOS QUE (RE)CONTAM A HISTÓRIA DE UM BRASIL- AINDA-COLÔNIA
}

\section{EVENT AND MEMORY (2): ENCOUNTERS OF DISCURSIVE GENRES WHICH (RE)TELL THE HISTORY OF A STILL- COLONIAL-BRAZIL}

\section{Décio Rocha*}

RESUMO: Este artigo procede a uma releitura de textos publicados em diferentes jornais brasileiros como desdobramento de evento ocorrido em Ouro Preto, Minas Gerais, aos 21 de abril de 1999. Será interrogado o modo pelo qual se articulam gênero do discurso e cenografia (MAINGUENEAU, 1989) nesses textos captados pela mídia, buscando-se responder às dificuldades criadas em torno de três tópicos centrais: (i) suposta presença de um duplo quadro cênico nesses textos; (ii) distância entre a referida dupla configuração cênica e os fenômenos de hibridismo de gêneros, que parecem antes remeter à noção de cenografia; (iii) papel desempenhado pela cenografia.

PALAVRAS-CHAVE: Cenografia. Gêneros do discurso. Duplo quadro cênico. Inconfidência Mineira.

ABSTRACT: This paper proposes a re-reading of texts published in different brazilian newspapers as an unfolding of an event occurred in Ouro Preto, Minas Gerais, on April 21, 1999. The articulation between genres and scenography (MAINGUENEAU, 1989) in these texts will be highlighted so as to respond to difficulties of three kinds: (i) the alleged presence of a double scenic framework in these texts; (ii) the distance between this double scenic setting and the phenomena of hybridity of genres, which would seem rather to refer to the notion of scenography; (iii) the role of scenography.

KEYWORDS: Scenography. Discursive genres. Double scenic framework. Minas Gerais Conspiracy. 


\section{ACONTECIMENTO E MEMÓRIA (2): ENCONTRO DE GÊNEROS DISCURSIVOS QUE (RE)CONTAM A HISTÓRIA DE UM BRASIL-AINDA-COLÔNIA}

Este trabalho retoma - para propor uma nova leitura - a análise de um córpus ${ }^{1}$ que serviu de base a texto publicado por ocasião das comemorações dos quinhentos anos do descobrimento do Brasil (ROCHA; SOUZA-E-SILVA, 2000), no qual se enfatizava a articulação dos seguintes dispositivos de uma semântica global (MAINGUENEAU, 2005) na produção de efeitos singulares de sentido: coenunciadores, tema, etos ${ }^{2}$, cenografia e código linguageiro. Mais especificamente, trata-se da releitura de notícias publicadas na mídia de informação que tiveram como motivação evento ocorrido em 21 de abril de 1999, quando o então governador de Minas Gerais, Itamar Franco, organizou em Ouro Preto um perfil no mínimo inusitado de solenidade de encerramento da Semana da Inconfidência: uma cerimônia de comemoração de evento cívico que, contando com o apoio de diferentes tendências de oposição do cenário político nacional, coincidiu / transformou-se em manifestação contra o governo do então presidente Fernando Henrique Cardoso ${ }^{3}$.

O objetivo central da presente discussão é justamente aprofundar o debate relativo à natureza do referido acontecimento de Ouro Preto: qual o evento ocorrido naquele 21 de abril? A comemoração do Dia de Tiradentes? Ou o ato de protesto contra o governo federal? Como se articulam, do ponto de vista discursivo, "a solenidade de comemoração da Inconfidência Mineira" e "a maior manifestação realizada contra o

\footnotetext{
*Universidade do Estado do Rio de Janeiro, CNPq, Professor Associado, rochadm@uol.com.br.

${ }^{1}$ Dada a frequência de uso do termo na área dos estudos da linguagem, penso ser adequado contribuir para que córpus (forma única no singular e no plural, a exemplo de "lápis") alcance a condição de palavra da língua portuguesa a ser dicionarizada. Aliás, uma rápida busca da grafia "córpus" no Google acadêmico já nos indica ser essa uma iniciativa apoiada por muitos.

${ }^{2} \mathrm{O}$ largo uso que se vem fazendo do conceito de etos justifica que lhe seja concedida "cidadania" em língua portuguesa, evitando-se a forma estrangeira ethos. Além de serem numerosos os compostos de “etos" (etologia, etografia, etocracia, etogenia, etc.), trata-se já de forma legitimada no Dicionário Houaiss da Língua Portuguesa.

${ }^{3}$ FHC, como ficou conhecido, foi presidente da República Federativa do Brasil em dois mandatos sucessivos: de 1995 a 1998 e de 1999 a 2002.
} 
governo FHC’? Uma reavaliação das análises já realizadas permitirá abordar a questão dos gêneros do discurso, focalizando em especial o encontro de noções como mescla ou hibridização de gêneros (MARCUSCHI, 2002), intertextualidade intergêneros (FIX, 2006), intergenericidade (KOCK, 2002), transmutação de gêneros (BAKHTIN, 1992) e cenografia (MAINGUENEAU, 1989).

Mantenho o mesmo córpus utilizado anteriormente, o qual foi circunscrito às matérias veiculadas no dia 22/04/99 em jornais de Minas Gerais (Estado de Minas e Diário da Tarde), Rio de Janeiro (O Globo e Jornal do Brasil) e São Paulo (Folha de S. Paulo e Estado de S. Paulo), sem qualquer preocupação de apreender as regularidades e variabilidades existentes entre os diferentes jornais. Os textos encontram-se reproduzidos em anexo e, no sentido de viabilizar seu tratamento, optou-se pela organização de dois conjuntos textuais:

- fragmentos de discurso relatado por intermédio dos quais os jornais permitem o acesso a uma representação de parte das interações verbais havidas por ocasião do evento em Ouro Preto;

- fragmentos que se referem à (dupla?) natureza do evento noticiado em cada jornal.

\section{FRAGMENTOS EM DISCURSO RELATADO: 0 INVESTIMENTO CENOGRÁFICO}

Os enunciados produzidos por ocasião do evento de 21 de abril de 1999 (seja esse evento qual for - solenidade de comemoração ou manifestação política) e que foram relatados por diferentes jornais no dia seguinte parecem operar no sentido de tornar indistintos o "fato-solenidade comemorativa" e o "fato-manifestação política": por meio do investimento em dispositivos enunciativos como um determinado perfil de coenunciadores, uma escolha temática, uma certa composição de etos e de código linguageiro, procedimentos que, em conjunto, poderiam remeter à construção de uma cenografia, tudo se passa como se o que acontecia então em Ouro Preto fosse mais um episódio da Conjuração Mineira do final do século XVIII. Do ponto de vista discursivo, quem ali se apresentava assumia o tom dos conjurados que, em sua luta pela libertação do país contra o domínio estrangeiro, conclamavam o povo, em tom grandiloquente, a não permitir que uma nova derrama tivesse lugar, segundo se anunciava pela ação do vendilhão da pátria. Lembrando que "uma formação discursiva não enuncia a partir de um sujeito, de uma conjuntura histórica e de um espaço objetivamente determináveis do exterior" (MAINGUENEAU, 1989, p.42), esforçando-se, antes, por construir uma cena que a enunciação simultaneamente produz e pressupõe para se legitimar, retomo algumas das atualizações dos referidos dispositivos enunciativos que corporificara naquela ocasião um "novo capítulo" da Inconfidência Mineira:

\subsection{Instituição de coenunciadores, de um tempo e de um espaço compatíveis com o que é tematizado}

Diário da Tarde: "Espero que o ar dessa praça libertária (Praça Tiradentes) possa trazer a coragem para dizer que, se quisermos salvar esse País, cada um terá que se transformar em um Tiradentes", afirmou ... Lula da Silva.

O Globo: O presidente de honra do PT, Luiz Inácio Lula da Silva, por exemplo, chamou o presidente Fernando Henrique Cardoso de Joaquim 
Silvério dos Reis (o traidor de Tiradentes), acusando-o de ser o "vendilhão da pátria”. (...)

O Globo: Itamar, o anfitrião da festa, disse que encontra alento no compromisso patriótico de Tiradentes: "Uma tocha acesa, luz que mostra o caminho". (...) Ao contrário do que pretendia o Governo, todos os esforços para isolar o povo mineiro foram inúteis - disse Itamar, que só se referia aos populares presentes como montanheses.

Folha de S. Paulo: O petista Luís Inácio Lula da Silva chamou FHC de "Joaquim Silvério dos Reis, imperador, falsário e vendilhão da pátria".

Estado de Minas: O petista [Lula da Silva] observou, ironicamente, que Fernando Henrique Cardoso, no dia de Tiradentes, provocou "uma nova derrama”, confiscando R\$39 milhões de Minas.

\subsection{Construção de um etos, representação do corpo do enunciador, um caráter e uma corporalidade que atuam como elementos legitimadores do modo pelo qual se enuncia:}

O Globo: O governador [Itamar] aproveitou para repetir que "Minas não permitirá que levem seus rios e suas usinas hidrelétricas". Nesta hipótese, "teremos confronto", ameaçou.

Estado de Minas: Itamar lembrou: "o povo, principal protagonista da história, pôde vir livremente à sua praça e dar vivas ao Tiradentes".

\subsection{Construção de um código linguageiro, dispositivo cuja função é explicitar que a enunciação não se dá por intermédio de uma língua, entendida como "veículo de transmissão de um dado conteúdo", mas por meio de um plurilinguismo irredutível:}

Jornal do Brasil: "Estamos de novo empenhados na defesa dos bens, da dignidade e da vida do povo brasileiro. Não estamos sós. Em todo o Brasil ecoam as vozes de Minas", assegurou [Itamar Franco].

Jornal do Brasil: "Um malogro a cada minuto mais evidente é o que se estampa aos olhos da nação. Para não se dizer mais".

Estado de Minas: Ganhou decibéis, com o apoio de milhares de pessoas na Praça Tiradentes, a promessa de Itamar Franco de "levantar a voz de Minas".

Constata-se, desse modo, a presença de fragmentos em discurso relatado ilustrativos da captação de uma cenografia que institui uma espécie de dilatação do tempo (naquele final de século XX, vivemos ainda o momento da luta pela independência do país), uma permanência do espaço (Ouro Preto, extensão de Vila Rica, ainda é o lócus de resistência), uma eternização dos mesmos personagens (Joaquim Silvério dos Reis ainda vive e somente a determinação de Tiradentes - todos nós - poderá combatê-lo) e dos mesmos "fatos" (uma nova "derrama" se anuncia com a confiscação de recursos destinados a Minas Gerais, iniciativa que urge combater). Em outras palavras, assiste-se aqui a um momento crucial da história brasileira no espaço de resistência de Ouro Preto, marcado pelo embate entre os ideais de Tiradentes e o entreguismo de Joaquim Silvério dos Reis; um episódio apenas compatível com um etos de combatividade e indignação e com o tom grandiloquente dos discursos inflamados que se tecem por intermédio do investimento em um código linguageiro. 


\section{AINDA ACERCA DE FRAGMENTOS EM DISCURSO RELATADO: INVESTIMENTO NA SITUAÇÃO EMPÍRICA DE 21 DE ABRIL DE 1999}

Como busquei enfatizar no item anterior, muitas das falas reportadas pela mídia no dia seguinte ao evento de Ouro Preto "mimetizavam" os discursos libertários de inspiração oitocentista. Tal procedimento se apresenta como o investimento em uma cenografia, implicando uma situação de enlaçamento paradoxal: para se legitimar, a enunciação simultaneamente produz e pressupõe uma dada cena (MAINGUENEAU, 1989, p.42). Ou seja: resgatando a palavra, o tom, os temas privilegiados dos conjurados de Vila Rica, a enunciação ganha legitimidade nos argumentos que expressa e, ao mesmo tempo, trabalha no sentido de imprimir visibilidade - e, desse modo, credibilidade - a essa mesma cena do passado, ora revitalizada discursivamente.

Para além dessa dimensão cenográfica, porém, também é possível recuperar nos enunciados relatados pela mídia algo que parece apontar mais inequivocamente para a situação empírica que dá respaldo ao evento de Ouro Preto, a saber, o descontentamento das esquerdas frente ao governo de Fernando Henrique Cardoso. Com efeito, não são raras as menções feitas aos desmandos e arbitrariedades de um governo central que precisa ser contido. Como argumentarei adiante, a explicitação de tal situação empírica característica do governo de FHC desempenhará um papel importante no debate relativo ao encontro de diferentes gêneros discursivos que pretendo desenvolver no próximo tópico.

A título de comprovação da referida ênfase em uma situação empírica típica desse abril de 1999 (e não mais reveladora dos embates da Inconfidência Mineira), proponho percorrer os seguintes fragmentos relatados pela mídia:

\subsection{Constatação de um país subjugado, que vive, naquele final de século $X X$, um momento de penúria:}

Diário da Tarde: [pronunciamento de Lula da Silva]: "pela primeira vez, um presidente deixa uma dívida de US\$500 bilhões e nem um tijolo colocado nesse País". "Até os (governos) militares construíram uma dívida, mas deixaram ativos", completou o dirigente petista, chamando Fernando Henrique Cardoso de "presidente-cupim - o que só destrói -" e "vendilhão da Pátria".

O Globo: Podemos chamar o Fernando Henrique Cardoso de o presidentecupim. Ele só soube destruir, não construiu nada. Ele acabou com a soberania do país e com as estatais. Ele colocou o país de joelhos diante dos credores internacionais. [discurso de Lula da Silva]

Jornal do Brasil: O governador afirmou que o estado e o país estão "subjugados por imposições que advêm de uma política econômica perversa e geradora de desemprego".

Folha de S. Paulo: Os discursos foram marcados por duras críticas ao governo FHC, principalmente relacionadas ... ao que a oposição chama de submissão do Brasil aos interesses internacionais. (...)

Estado de S. Paulo: Em seu discurso, Lula chamou Fernando Henrique de "presidente-cupim", que só sabe destruir. 


\subsection{Identificação dos atores que tomam parte nos embates de 1999 entre descontentes e governo FHC:}

Estado de S. Paulo: "Não vamos dividir a oposição em palavras de ordem", afirmou o presidente do PT, José Dirceu. "Estamos mais unidos do que nunca", reforçou o presidente do PDT, Leonel Brizola. "Há divergências, mas vamos continuar juntos".

Estado de Minas: "Esse governo que permite que se dê a banqueiros bilhões é o mesmo governo que, mais uma vez, fez um bloqueio de recursos de Minas, disse [Itamar Franco]. E enfatizou sua reclamação: "Por que esse governo não pode dar nada a Minas mas pode dar bilhões aos banqueiros?".

Diário da Tarde: [pronunciamento de Lúcio Urbano, presidente do Tribunal de Justiça] - "Reparem, senhores, que os inconfidentes buscaram aos americanos arrimo para a revolução da independência do Brasil, enquanto hoje se busca a rica nação do Norte para a entrega de nossas riquezas, em recurvada vassalagem ao capital volátil, sabendo-se, embora, que isso se traduz em recessão, em miséria para o povo brasileiro, ...”

[pronunciamento de Leonel Brizola]: “Aos pés do monumento a Tiradentes eu faço um apelo ao Fernando Henrique e seu companheiro de chapa, Marco Maciel, para que ambos pensem seriamente em renunciar".

Jornal do Brasil: "Enquanto houver um presidente falsário, que cometa o estelionato eleitoral que o Fernando Henrique Cardoso cometeu, um presidente que minta à nação brasileira como ele mentiu, nós não podemos sair das ruas até que a gente consiga ter um governo comprometido com os anseios do povo", conclamou o presidente de honra do PT ... (...)

Estado de S. Paulo: “... para bancos e banqueiros, [FHC] permite que se dê milhões", atacou [Itamar Franco].

\subsection{Construção de uma proposta de ação como resistência a uma nova "derrama":}

Diário da Tarde: [pronunciamento de Miguel Arraes]: "Vamos reverter esse quadro com a população nas ruas", previu o velho líder socialista, desejando que esse ato ... signifique uma larga convergência das forças políticas e sociais na defesa da soberania do nosso País, que Tiradentes buscou no seu tempo".

O orador oficial [Lúcio Urbano] terminou sua fala invocando os inconfidentes para que eles não permitam "que a pátria, sonhada em seus projetos, volte à condição de colônia" nem que consintam que os dirigentes se curvem "como lacaios aos interesses da economia sem rosto das organizações internais". Pediu ainda a volta do espírito de Tiradentes "porque a nacionalidade anda à beira do naufrágio".

Jornal do Brasil: "Neste momento, querem levar nossos rios, levar as nossas usinas hidrelétricas. Mas nós não permitiremos. Nós vamos dizer aos homens do poder que não tentem tirar os nossos rios, levar as nossas hidrelétricas, porque, aí sim, teremos o confronto." [discurso de Itamar Franco]

Folha de S. Paulo: Lula defendeu ontem que a oposição promova "movimentos fortes" nas ruas contra o governo.

"Neste momento, querem levar os nossos rios e as nossas usinas hidrelétricas. Daqui dessa praça não permitiremos."

Estado de S. Paulo: ... [Itamar Franco] afirmou que não permitirá a privatização das hidrelétricas. "Vamos dizer ao homem do poder que não tente desviar os nossos rios porque, aí, teremos confronto". 
Como dito anteriormente, os fragmentos elencados nesses três agrupamentos priorizam a situação vivida em 1999, primeiro ano do segundo mandato presidencial de FHC, o que não impede que em momentos bastante pontuais seja "relembrado" o investimento na cenografia já conhecida. É assim, por exemplo, que se localizam nesse item algumas poucas referências que apontam novamente em direção ao século XVIII: após ser qualificado como "presidente-cupim", FHC é ainda uma vez intitulado "vendilhão da pátria"; faz-se uma menção explícita à experiência dos inconfidentes, desejosos de independência, junto aos americanos; registram-se três referências a Tiradentes como base segura para uma ação libertária.

Eis, desse modo, construído o cenário que traduz uma tensão entre uma mesma cena e uma sucessão de cenas: o combate (empreendido seja pelos conjurados de Minas, seja pelos aliados de Itamar Franco) aos desmandos de um poder central usurpador (seja este o governo português frente à realidade do Brasil-colônia do século XVIII, seja o governo republicano de FHC que se alia ao capital especulativo internacional); a manifestação da liderança oposicionista, identificada ao destino de Tiradentes, contra FHC, que perpetua a tradição de Joaquim Silvério dos Reis em sua aliança com os credores internacionais; a derrama que, a exemplo do que ocorrera naquele final de século XVIII, se atualiza sob o modo do confisco do patrimônio da nação. Minas Gerais, Ouro Preto, Praça Tiradentes e arredores, escadarias do Museu da Inconfidência: espaços que não mais apenas remetem às coordenadas geográficas de realização do evento, transformando-se em insígnia da capital da oposição. Os inconfidentes / membros de partidos de esquerda não permitirão "que a pátria ... volte à condição de colônia". Afirmação de um etos de coesão, de abnegação e de persistência na luta pela construção da soberania nacional, simbolicamente encenado na cerimônia de entrega da Grande Medalha da Inconfidência aos presentes. Redimensionamento do Dia de Tiradentes, que perde sua condição cronológica de "evento rememorativo" para se instituir em momento de perpetuação dos discursos passionais de construção de uma nova nação. Afinal, "a luta pela soberania nacional não acabou com Tiradentes. Ela continua". E continua protagonizada por descontentes deste final de século XX, representados por diferentes partidos de esquerda que ora ganham coesão, trabalhadores, estudantes e integrantes do Movimento dos Trabalhadores Rurais Sem Terra.

\section{NOVOS FRAGMENTOS DE RELATOS DA MÍDIA: 0 ENCONTRO DE GÊNEROS DISCURSIVOS}

Conforme será visto adiante no quadro 1, percebe-se nos relatos feitos pela mídia uma certa indecisão acerca do "fato" ocorrido naquele 21 de abril de 1999, tendo em vista o recurso a designações que apontam ora para o "fato-manifestação política", ora para o "fato-solenidade de comemoração".

A esse respeito, dois fenômenos me parecem relevantes: (i) o quadro cênico (MAINGUENEAU, 2013, p.97) não é unívoco, sendo habitado minimamente por uma dupla cena genérica (e mesmo uma dupla cena englobante); (ii) a cenografia não chega a apagar o quadro cênico. Apresento, a seguir, os argumentos a que recorro para a leitura que proponho.

Falar de uma dupla cena genérica poderia sugerir um debate em torno de temas como os indicados ao início deste trabalho: mescla de gêneros, hibridização, intertextualidade intergêneros, ou ainda intergenericidade. Argumentarei em sentido 
contrário, indicando que os conceitos aqui referidos coincidem não exatamente com o que pretendo iluminar - o de dupla cena genérica -, mas, mais plenamente, com o de cenografia (MAINGUENEAU, 1989). Adianto desde já que, ao falar dessa dupla cena genérica, também não penso na proposta bakhtiniana de absorção e transmutação de gêneros primários no interior de gêneros secundários (BAKHTIN, 1992, p.281).

Inicio, desse modo, uma abordagem da não univocidade do quadro cênico por intermédio do levantamento de referências feitas nos discursos da mídia aos reformulantes "manifestação política" e "solenidade / comemoração"4:

Quadro 1 - Ocorrências dos reformulantes "manifestação política" e "comemoração" em textos publicados na mídia em 22/04/1999

\begin{tabular}{|c|c|c|}
\hline & "manifestação política" & "solenidade / comemoração" \\
\hline $\begin{array}{c}\text { Estado } \\
\text { de } \\
\text { Minas }\end{array}$ & $\begin{array}{l}\text { um grande ato de } \\
\text { protesto contra a política } \\
\text { econômica do governo } \\
\text { federal } \\
\text { o maior ato público de } \\
\text { protesto contra a política } \\
\text { econômica do presidente } \\
\text { o ato público realizado } \\
\text { ontem em Ouro Preto }\end{array}$ & $\begin{array}{l}\text { a comemoração do dia da Inconfidência Mineira } \\
\text { ontem, em Ouro Preto } \\
\text {. Comemoração do } 21 \text { de Abril em Ouro Preto } \\
\text {. as comemorações da Inconfidência Mineira, em } \\
\text { Ouro Preto } \\
\text {. comemoração do Dia da Inconfidência. } \\
\text {. Comemorações do Dia da Inconfidência (2) } \\
\text {. comemorações da Inconfidência Mineira (2) } \\
\text { a(s) comemoração/ões } \\
\text {. a cerimônia da Inconfidência Mineira } \\
\text { Cerimônia lembrando a Inconfidência Mineira } \\
\text {. solenidade da Inconfidência Mineira, em Ouro } \\
\text { Preto } \\
\text { solenidades do Dia da Inconfidência, em Ouro } \\
\text { Preto } \\
\text { a solenidade } \\
\text { a festa da Inconfidência } \\
\text { festa de Ouro Preto } \\
\text { festa do } 21 \text { de Abril em Ouro Preto }\end{array}$ \\
\hline $\begin{array}{c}\text { Diário } \\
\text { da } \\
\text { Tarde }\end{array}$ & $\begin{array}{l}\text { ato de protesto contra a } \\
\text { política do governo } \\
\text { federal } \\
\text {. ato público de protesto } \\
\text { contra o governo feder } \\
\text {. larga convergência das } \\
\text { forças políticas e sociais } \\
\text { na defesa da soberania do } \\
\text { nosso País } \\
\text {. a "festa do basta" }\end{array}$ & $\begin{array}{l}\text {. solenidade comemorativa de } 21 \text { de Abril } \\
\text { solenidade comemorativa da Inconfidência } \\
\text { Mineira (4) } \\
\text {. a solenidade de comemoração da Inconfidência } \\
\text { Mineira } \\
\text { a solenidade (3) } \\
\text { solenidade em homenagem a Tiradentes } \\
\text {. esse ato (a comemoração da Inconfidência } \\
\text { Mineira) } \\
\text {. comemoração do Dia da Inconfidência (2) } \\
\text { a comemoração do Dia da Inconfidência, ontem, } \\
\text { em Ouro Preto } \\
\text { comemorações do } 21 \text { de abril }\end{array}$ \\
\hline
\end{tabular}

\footnotetext{
${ }^{4}$ Quando for o caso, indicarei entre parênteses o número de ocorrências de um mesmo reformulante.
} 


\begin{tabular}{|c|c|c|}
\hline & & a cerimônia do 21 de abril \\
\hline O Globo & $\begin{array}{l}\text { ato contra FH } \\
\text {. a maior manifestação } \\
\text { contra o Governo no Dia } \\
\text { da Inconfidência } \\
\text { manifestação }\end{array}$ & $\begin{array}{l}\text { comemoração ao Dia de Tiradentes } \\
\text {. a festa }\end{array}$ \\
\hline $\begin{array}{l}\text { Jornal } \\
\qquad \text { do } \\
\text { Brasil }\end{array}$ & $\begin{array}{l}\text { - protestos em Ouro Preto } \\
\text { manifestação contra o } \\
\text { presidente } \\
\text {. a maior manifestação } \\
\text { realizada contra o } \\
\text { presidente } \\
\text { manifestação }\end{array}$ & . comemoração da Inconfidência Mineira \\
\hline $\begin{array}{l}\text { Folha } \\
\text { de S. } \\
\text { Paulo }\end{array}$ & $\begin{array}{l}\text { protesto } \\
\text { - manifestação contra o } \\
\text { presidente } \\
\text { uma cerimônia de } \\
\text { protesto }\end{array}$ & \\
\hline $\begin{array}{l}\text { Estado } \\
\text { de } S . \\
\text { Paulo }\end{array}$ & $\begin{array}{l}\text { uma } \\
\text { confraternização } \\
\text { esquerda brasileira } \\
\text { um grande protesto } \\
\text { contra o governo federal }\end{array}$ & $\begin{array}{l}\text {. comemoração do Dia de Tiradentes } \\
\text {. comemoração do Dia de Tiradentes em Ouro } \\
\text { Preto }\end{array}$ \\
\hline
\end{tabular}

Fonte: ROCHA; SOUZA-E-SILVA, 2000.

Do ponto de vista quantitativo, os resultados obtidos indicam que os reformulantes privilegiados neste subcórpus referem-se ao "fato-comemoração": 39 ocorrências para designar o evento comemorativo e apenas 19 para designar a manifestação política.

Tal alternância de designações é significativa, se lembrarmos que uma manifestação e uma cerimônia de comemoração implicam coerções bastante diversas: uma manifestação é um ato eminentemente político, pressupondo a presença de sujeitos que expressam sua não concordância com uma dada situação, que apresentam uma pauta de reivindicações, que se definem como ocupando um lugar de oposição; já uma cerimônia de comemoração implica um exercício cívico de enaltecimento de um fato qualquer, mediante a presença de sujeitos que, em relação de aliança, ratificam o episódio comemorado, homenageando-o naquilo que ele apresenta de memorável e de definidor de uma dada comunidade. A partir dessa caracterização bastante sumária de cada um dos eventos, claro está que em cada um predominarão gêneros do discurso que marcarão sua singularidade: os discursos inflamados, acusatórios, as faixas de protesto, etc., serão presença certa nas manifestações, enquanto os discursos laudatórios darão o tom das cerimônias de comemoração.

Tendo em vista a alternância entre "manifestação" e "comemoração" que parece ritmar a composição desse córpus, procedeu-se ao levantamento dos sintagmas que explicitam a relação instituída entre ambas a fim de verificar de que modo os discursos da imprensa constroem a articulação entre o "fato-manifestação política" e o "fato-solenidade / comemoração". Verificou-se que tal articulação ocorre sob três 
modalidades distintas:

\subsection{0 "fato-comemoração" é introduzido na qualidade de momento em que coincidentemente ocorre o "fato-manifestação política":}

Estado de Minas: Cerimônia lembrando a Inconfidência Mineira reúne os líderes da oposição ao governo federal em Ouro Preto.

Itamar Franco, principal anfitrião do ato público realizado ontem em Ouro Preto, durante as comemorações da Inconfidência Mineira.

... as autoridades e lideranças de oposição que participaram das comemorações do Dia da Inconfidência.

Diário da Tarde: As oposições ao presidente Fernando Henrique tomaram conta da Praça Tiradentes ... em Ouro Preto, na solenidade comemorativa de 21 de Abril.

Lula aproveitou a solenidade para voltar a fazer críticas ao presidente da República.

$O$ Globo: O governador Itamar Franco se vangloriou de ter organizado a maior manifestação contra o Governo no Dia da Inconfidência.

Jornal do Brasil: No dia de Tiradentes, Itamar lidera protestos em Ouro Preto Itamar leva cerca de 20 mil à praça no dia de Tiradentes

Ouro Preto, MG - O governador de Minas, Itamar Franco (PMDB), conseguiu, ontem, na comemoração da Inconfidência Mineira, o que planejou durante dois meses.

\subsection{0 "fato-manifestação política" é apresentado como modo de atualização do "fato-comemoração":}

Estado de Minas: ... o tom oposicionista que o governador Itamar Franco quis dar ontem à festa de Ouro Preto.

[José Dirceu] classificou a comemoração como "sinal de novos tempos".

Diário da Tarde: ... desejando que esse ato (a comemoração da Inconfidência Mineira) signifique uma larga convergência das forças políticas e sociais na defesa da soberania do nosso País ...

$O$ Globo: O governador Itamar Franco reuniu os principais líderes da oposição em Ouro Preto, em comemoração ao Dia de Tiradentes.

Folha de S. Paulo: [A solenidade de entrega da Medalha da Inconfidência] neste ano ... foi planejada como uma cerimônia de protesto.

\subsection{0 "fato-comemoração" e o "fato-manifestação política" são apresentados como eventos distintos e sucessivos, sendo a manifestação uma "mutação" da comemoração:}

Estado de Minas: ... a comemoração do dia da Inconfidência Mineira ontem, em Ouro Preto, conseguiu transformar-se num grande ato de protesto contra a política econômica do governo federal.

Normalmente, eles [lideranças do MST, da CUT e da UNE] marcariam presença na solenidade da Inconfidência Mineira, em Ouro Preto (...) Pela primeira vez, esses movimentos - e suas lideranças - se tornaram protagonistas da Inconfidência.

Itamar Franco conseguiu o que queria: transformar a solenidade no maior ato público de protesto contra a política econômica do presidente

Diário da Tarde: A solenidade se transformou num ato de protesto contra a 
política do governo federal.

... o governador Itamar Franco conseguiu o seu objetivo ao transformar a solenidade num ato público de protesto contra o governo federal.

$O$ Globo: A histórica cidade de Ouro Preto transformou-se na capital da oposição ontem, no Dia de Tiradentes.

Estado de S. Paulo: Ouro Preto - A comemoração do Dia de Tiradentes em Ouro Preto, ontem, transformou-se numa grande confraternização da esquerda brasileira.

(...) Este ano, ... Itamar transformou o evento num grande protesto contra $\mathrm{o}$ governo federal.

Com base nos dados que se expõem em cada um desses subtópicos, parece preservada a "integridade" de uma dupla cena genérica: reconhece-se, por um lado, a ocorrência de uma solenidade comemorativa e, por outro, a evidência de uma manifestação política. O que parece variar é precisamente o modo pelo qual essas duas cenas se articulam. Senão, vejamos: em 3.1, institui-se uma simultaneidade entre os dois eventos; em 3.2, uma cena apresenta-se como modo de atualização da outra; finalmente, em 3.3, uma cena sucede à outra. Seja como for, a integridade dessa dupla cena parece garantida, seja qual for o modo de encontro entre elas. Tal constatação permite que se afirme algo da seguinte ordem: "o que ali se realiza é uma solenidade de comemoração e uma manifestação política".

O que concluir de tal duplicidade de cenas genéricas? Em primeiro lugar, conforme foi visto, os fragmentos presentes nesse segundo subcórpus remetem à solenidade comemorativa do evento "Conjuração Mineira" e à informação do público leitor sobre o evento "manifestação política". Opta-se, dessa forma, pela justaposição das coordenadas espaçotemporais dos dois eventos - manifestação política e comemoração -, o que garante preservar a identidade de cada um dos "fatos", sob modos variados: a manifestação política coincide com o momento da comemoração (mas permanecem sendo eventos distintos); a manifestação política é um modo de atualização de um outro evento (a Conjuração Mineira); a manifestação política é uma transformação do evento "comemoração".

Em segundo lugar, se aqui se assume uma duplicidade de cenas genéricas - a solenidade comemorativa e a manifestação política de oposição -, parece-me lícito supor paralelamente a existência de uma dupla cena englobante. Entendida como o tipo de discurso que é preciso saber reconhecer a fim de se dispor da possibilidade de interpretar o mais adequadamente possível um texto (MAINGUENEAU, 2013, p.96), a cena englobante corresponde precisamente ao universo de sentido - religioso, político, didático, literário etc. - no interior do qual um determinado gênero ganhará consistência. Ora, se se reconhece nos fragmentos organizados para análise a presença de um duplo gênero de discurso - uma solenidade comemorativa e uma manifestação de oposição a um governo - é coerente postular, em relação à primeira dessas cenas genéricas, a evidência de uma cena englobante que defino como cívica; já em relação à cena genérica da manifestação contra o governo, uma cena englobante política. Tem-se, assim, um duplo quadro cênico cuja atualização obedece a um tríplice modo de articulação, segundo busquei sustentar: de um lado, no interior de uma cena englobante típica das solenidades cívicas, a comemoração do 21 de abril como data simbólica expressiva da ação patriótica e libertária dos conjurados de Minas (uma comemoração que não deixará de exibir suas marcas enquanto gênero, se forem consideradas a execução de ações como, por exemplo, a entrega da medalha de Tiradentes a um 
brasileiro que tenha se distinguido naquele ano, com o pronunciamento de discursos compatíveis com tal cena); de outro lado, inserido em uma cena englobante da ordem do político, a manifestação de descontentes com o status quo, inconformados com a sofrível qualidade das relações sociais que ritmam a realidade do país e que, por essa razão, é preciso transformar por meio de uma ação orquestrada da qual todos participem.

Direi ainda que a duplicidade genérica de que ora se fala é um fenômeno que nada tem a ver com a hibridização de gêneros (ou com qualquer outra designação conceitual que lhe seja aparentada, conforme já tive a ocasião de enumerar anteriormente). Para apoiar o ponto de vista que defendo, retomo a reflexão de Lara (2009), que sustenta a existência de uma relação de sinonímia entre diferentes termos regularmente utilizados para fazer referência ao tema abordado:

\begin{abstract}
Transgressão, intertextualidade intergêneros, intertextualidade intragenérica, intertextualização, imitação/captação, mudança de cenografia. A diversidade de termos/conceitos, ainda que haja pontos significativos de convergência entre eles, mostra que não se trata de uma questão simples. Aliás, a dificuldade de abordar a noção (mais ampla) de hibridismo ou mescla de gêneros é corolária da própria complexidade e extensão do conceito de gêneros. Afinal de contas, nem sempre é fácil decidir sobre os limites entre um gênero e outro, reconhecer subgêneros no interior de um gênero maior e mesmo arrolar critérios que permitam enquadrar um determinado texto/discurso num gênero "x" e não num gênero " $y$ ". (LARA, 2009)
\end{abstract}

Ora, o que se comprova com base nos exemplos fornecidos por diferentes autores que abordam quaisquer dos conceitos elencados por Lara (2009) é que realmente, sob denominações variadas, esses hibridismos podem grosso modo ser compreendidos em variação entre duas margens: enfatizando traços de produção textual que parecem se prender às novas tecnologias, a primeira dessas margens caracterizaria os hibridismos como marcas dos gêneros que emergiram no último século, no contexto das mais diversas mídias; uma segunda margem retirará a ênfase colocada sobre o caráter datado do fenômeno, entendendo a hibridização como mescla essencial em que um gênero assume a função de outro. Acrescente-se que, no espaço entremargens, todo um leque de denominações e nuanças se revela possível.

Quero ainda retomar um aspecto da reflexão de Lara (2009) que diz respeito à aproximação feita entre, por um lado, as ideias de hibridização, intertextualidade intergêneros, transgressão, etc., e, por outro, a noção de cenografia formulada por Maingueneau (1989), concordando em tese com sua posição: é, com certeza, da produção de cenografias que se trata quando autores diversos, recorrendo a denominações diversas, tematizam um artigo de opinião que se apresenta sob a forma de poema (MARCUSCHI, 2002, p.30), ou então quando um anúncio de xampu se apresenta sob a forma de uma capa de revista (LARA, 2010, p.25). Tais estratégias são recorrentes muito especialmente nos discursos da publicidade, os quais exigem sempre o inusitado, de modo a captar / capturar o consumidor, conforme se atesta no fragmento que cito a seguir:

No clima acadêmico e profissional competitivo de hoje, os gêneros raramente mantêm valores estáticos. Esses valores são cada vez mais explorados pelos profissionais experientes para criar gêneros mais híbridos, especialmente 
como resultado da natureza fortemente compulsiva das atividades promocionais e publicitárias. (BATHIA, 2001, p.106)

O mesmo parece se confirmar nas palavras iniciais do resumo que introduz o artigo da autoria de Fix (2006), quando a autora faz menção à "transgressão" intergenérica como "fenômeno cada vez mais frequente":

O trabalho presente investiga o fenômeno cada vez mais frequente da "transgressão de limites" que encontramos no mundo dos textos literários e não literários em formas que utilizam a intertextualidade tipológica. (FIX, 2006, p.262)

O recurso a essa dimensão estratégica das cenografias em publicidades é igualmente reconhecido por Maingueneau, que chega a mencionar o papel de "cilada" que a cenografia vem cumprir no referido contexto:

A cenografia leva o quadro cênico a se deslocar para o segundo plano; a leitora de nossa publicidade [dos produtos Week-End], por exemplo, cai numa espécie de cilada, pois recebe inicialmente o texto como uma conversa telefônica, e não como uma propaganda de um gênero determinado. (MAINGUENEAU, 2013, p.97)

Penso, no entanto, que, para além da referida dimensão estratégica de uma cenografia em um contexto como o dos discursos publicitários, a função das cenografias, segundo a ótica de Maingueneau, seja outra, caracterizando-se por um grau de complexidade que nenhum compromisso mantém com o projeto intencional - de captação de um consumidor, por exemplo - que costuma ser o caso na produção de textos construídos com base em uma estratégia publicitária. Tal complexidade já ficou sinalizada ao início do segundo item deste artigo, quando menciono a noção de enlaçamento paradoxal que caracteriza as cenografias. Aqui, retomo o que diz o autor a respeito:

Com efeito, tomar a palavra significa, em graus variados, assumir um risco; a cenografia não é simplesmente um quadro, um cenário, como se o discurso aparecesse inesperadamente no interior de um espaço já construído e independente dele: é a enunciação que, ao se desenvolver, esforça-se para constituir progressivamente o seu próprio dispositivo de fala.

A cenografia implica, desse modo, um processo de enlaçamento paradoxal. Logo de início, a fala supõe uma certa situação de enunciação que, na realidade, vai sendo validada progressivamente por intermédio da própria enunciação. Desse modo, a cenografia é ao mesmo tempo a fonte do discurso $e$ aquilo que ele engendra. (...) Quanto mais avançamos na leitura da propaganda "Week-End", mais nos convencemos de que o telefonema de uma amiga constitui a melhor via de acesso a esse produto. (MAINGUENEAU, 2013, p.97-98)

$\mathrm{Na}$ reflexão do autor, fica bastante claro que, mesmo no caso dos discursos publicitários, situação na qual não se pode abrir mão de uma estratégia persuasiva junto ao consumidor, a construção de uma cenografia continua exercendo seu papel de enlaçamento paradoxal ao pressupor e, ao mesmo tempo, produzir progressivamente a cena que legitimará o dito. 


\section{EPÍLOGO: DUPLICIDADE DE QUADROS CÊNICOS, CENOGRAFIA E REQUALIFICAÇÃO DE UM PAÍS}

A tensão entre o "fato-solenidade comemorativa" e o "fato-manifestação política" pode ser em grande parte explicada pelo dispositivo enunciativo de captação de uma cena validada - a dos "discursos grandiloquentes da Conjuração Mineira" -, assumida no plano da cenografia pelos participantes do evento de Ouro Preto. Com base em tal dispositivo, um duplo movimento parece ter sido possibilitado:

- a solenidade comemorativa cumpre com muito mais vigor sua função de atualização do episódio histórico representado pela Conjuração Mineira: do século XVIII, a Conjuração Mineira avança no tempo, estendendo-se até aquele mês de abril de 1999;

- a manifestação política projetada pelos discursos de oposição recua no tempo: de fato da atualidade (oposição a FHC), passa a integrar uma tradição já antiga, a saber, a tradição de oposição aos governos despóticos.

Torna-se possível, desse modo, perceber que são as práticas de linguagem que aí se atualizam que permitem uma requalificação do empírico, reflexão sobre a qual trabalhei em textos anteriores ao tematizar a ideia de linguagem-intervenção (ROCHA, 2013a), função que privilegia não a mera representação de fatos, mas a produção mesma de uma dada qualidade do real. Assim é que o dispositivo cenográfico permite consolidar algo que até então não havia sido possível: a construção, na qualidade de "conjurados", de um único bloco oposicionista contra os desmandos do poder central, quando sabemos que os diferentes partidos políticos que fazem oposição a $\mathrm{FHC}$ não representavam, naquele final de século $\mathrm{XX}$, um bloco coeso, por força de divergências interpartidárias não resolvidas.

A força do dispositivo cenográfico como elemento facilitador dessa função de intervenção da linguagem ainda se deixa apreender na nova versão histórica que permite então produzir: finalmente, Tiradentes não é derrotado, pois agora somos capazes de identificar a tempo - e com segurança - o ardiloso "vendilhão da pátria". É possível, assim, reescrever um episódio da história desse país: a consagração de uma conjuração que terá êxito, por intermédio da união das forças de oposição contra o governo federal, anunciando-se desde já o pedido de renúncia de FHC e a convocação de nova eleição presidencial. Esperança, enfim, de superação dessa (longa) etapa de um Brasil-ainda-esempre-colônia.

A partir do encontro de dois gêneros - comemoração cívica e manifestação política - que se articulam sem se confundir, a enunciação vai gradativamente produzindo a cenografia que já a legitima de início. Tendo em vista a força que é capaz de exercer por meio desse enlaçamento paradoxal, uma cenografia parece, com efeito, não se situar no mesmo plano dos demais dispositivos previstos pela semântica global de Maingueneau (2005) - posição dos coenunciadores, cronografia, topografia, etos, código linguageiro, modos de coesão etc. -, mas, antes, pairar sobre todos esses dispositivos para orquestrá-los em necessária aliança. Razão pela qual penso que "a distância que separa gêneros e cenografias é da mesma ordem da distância que distingue 
formas (estabilizadas no tempo e no espaço) e forças (em efervescência)" (ROCHA, 2013b, p.157).

\section{REFERÊNCIAS}

BAKHTIN, M. Estética da Criação Verbal. São Paulo: Martins Fontes, 1992.

BHATIA, V. K. Análise de gêneros hoje. Revista de Letras n. ${ }^{\circ} 23$. vol. 1/2. jan./dez. Tradução de Benedito G. Bezerra. Fortaleza: Edições UFC, 2001, p. 102-115.

FIX, U. O cânone e a dissolução do cânone. A intertextualidade tipológica - um recurso estilístico "pós-moderno"? Revista de Estudos da Linguagem.v. 14, n. 1. Belo Horizonte: Faculdade de Letras da UFMG, jan./jun., 2006, p. $261-281$.

KOCH, I.G.V. Desvendando os segredos do texto. São Paulo: Contexto, 2002.

LARA, G. M. P. Uma proposta para a abordagem dos gêneros em sala de aula. Disponível em: ucs.br/ucs/tplSiget/extensao/agenda/eventos/vsiget/portugues/anais/textos autor/arquivos/uma_proposta_para_a_abordagem_dos_generos_em_sala_de_aula.pdf. Acesso em: 21/02/2014.

. Transgredindo os gêneros do discurso: entre a teoria e a prática. Belo Horizonte: Faculdade de Letras da UFMG. 2010.

MAINGUENEAU, D. Novas Tendências em Análise do Discurso. Campinas: Pontes, 1989.

—. Gênese dos discursos. Curitiba: Criar, 2005.

Análise de Textos de Comunicação. Trad. de Maria Cecília Souza-e-Silva e Décio Rocha. 6a. Ed. ampliada. São Paulo: Cortez, 2013.

MARCUSCHI, L.A. Gêneros textuais: definição e funcionalidade. In: DIONÍSIO, A.P.; MACHADO, A.R.; BEZERRA, M.A. Gêneros Textuais \& Ensino. Rio de Janeiro: Lucerna, 2002, p. $19-36$.

ROCHA, D. Circunscrevendo um caminho em Análise do discurso: linguagemrepresentação e linguagem-intervenção. Intersignos (Rio de Janeiro), v. 6, 2013a, p. 6782.

Cartografias em Análise do Discurso: rearticulando as noções de gênero e cenografia. Revista DELTA 29 nº 1 . São Paulo: Ed. PUCSP, 2013b, p. 135-159.

; SOUZA-E-SILVA, M.C.P. de. Acontecimento e Memória: Discursos que (Re)contam a História do Brasil-colônia. In: BARROS, D. L. P. de (org.). Os Discursos 
do descobrimento: 500 e mais anos de discursos. São Paulo: Ed. Da USP; FAPESP, 2000, p. $193-206$. 
ANEXO: Sintagmas em que figuram os reformulantes de "manifestação política" e "comemoração" nos seis jornais selecionados

\section{Estado de Minas}

. a comemoração do dia da Inconfidência Mineira ontem, em Ouro Preto, conseguiu transformar-se num grande ato de protesto contra a política econômica do governo federal.

. Comemoração do 21 de Abril em Ouro Preto teve muita gente ...

- [Itamar Franco] soube usar muito bem a cerimônia da Inconfidência Mineira.

. durante as comemorações da Inconfidência Mineira, em Ouro Preto.

. O prefeito de Ouro Preto ... foi amplamente vaiado ontem, durante a festa da Inconfidência ...

. Normalmente, eles [lideranças do MST, da CUT e da UNE] marcariam presença na solenidade da Inconfidência Mineira, em Ouro Preto (...) Pela primeira vez, esses movimentos - e suas lideranças - se tornaram protagonistas da Inconfidência.

. Cerimônia lembrando a Inconfidência Mineira reúne os líderes da oposição ao governo federal em Ouro Preto.

. Foi a primeira vez que o povo foi chamado a participar das comemorações do Dia da Inconfidência ...

. Vinte mil pessoas ... lotaram ontem a Praça Tiradentes, em Ouro Preto, durante as comemorações da Inconfidência Mineira.

- Itamar Franco conseguiu o que queria: transformar a solenidade no maior ato público de protesto contra a política econômica do presidente ...

. Em meio às comemorações ...

. o tom oposicionista que o governador Itamar Franco quis dar ontem à festa de Ouro Preto.

- [José Dirceu] classificou a comemoração como "sinal de novos tempos".

- Servidores da educação aproveitam solenidades do Dia da Inconfidência, em Ouro Preto, ...

. o povo assistiu de perto à festa do 21 de Abril em Ouro Preto.

- Grupos de professores e servidores do ensino chegaram à cidade - para a comemoração do Dia da Inconfidência ...

. Itamar Franco, principal anfitrião do ato público realizado ontem em Ouro Preto, durante as comemorações da Inconfidência Mineira.

. as autoridades e lideranças de oposição que participaram das comemorações do Dia da Inconfidência.

\section{Diário da Tarde}

. As oposições ao presidente Fernando Henrique tomaram conta da Praça Tiradentes ... em Ouro Preto, na solenidade comemorativa de 21 de Abril.

. A afirmativa foi feita ontem, em Ouro Preto, pelo governador Itamar Franco, durante a solenidade comemorativa da Inconfidência Mineira.

. A solenidade se transformou num ato de protesto contra a política do governo federal. Foi a primeira vez que os partidos de esquerda participaram ativamente da solenidade em homenagem a Tiradentes.

. A Praça Tiradentes ficou lotada e o governador Itamar Franco conseguiu o seu objetivo 
ao transformar a solenidade num ato público de protesto contra o governo federal.

. Orador oficial da cerimônia do 21 de abril, o desembargador Lúcio Urbano ...

- A medida [bloqueio financeiro realizado pelo governo federal contra Minas], comparada pelos governadores, dirigentes sindicais e partidários que participaram da solenidade comemorativa da Inconfidência Mineira, como uma "nova derrama", ...

. Lula aproveitou a solenidade para voltar a fazer críticas ao presidente da República.

. em Ouro Preto, a solenidade comemorativa da Inconfidência Mineira.

- desejando que esse ato (a comemoração da Inconfidência Mineira) signifique uma larga convergência das forças políticas e sociais na defesa da soberania do nosso País

- [O Sindifisp] marcou presença na comemoração do Dia da Inconfidência com 200 manifestantes.

. na comemoração do Dia da Inconfidência, ontem, em Ouro Preto ...

- A solenidade de comemoração da Inconfidência Mineira levou ontem a Ouro Preto

. Para participar da "festa do basta", conforme classificou ... José Genoíno

- A participação popular foi ... um traço marcante da comemoração do Dia da Inconfidência.

- para fazer a abertura da solenidade comemorativa da Inconfidência Mineira.

- [o governo do Estado de Minas] como organizador oficial das comemorações do 21 de abril ...

\section{O Globo}

. Itamar reúne oposição em ato contra FH

. O governador Itamar Franco reuniu os principais líderes da oposição em Ouro Preto, em comemoração ao Dia de Tiradentes.

. Lula compara FH ao traidor Joaquim Silvério dos Reis

. A histórica cidade de Ouro Preto transformou-se na capital da oposição ontem, no Dia de Tiradentes. (...) Itamar, o anfitrião da festa, ...

. Vinte mil pessoas na Praça Tiradentes

. Ouro Preto (MG). O governador Itamar Franco se vangloriou de ter organizado a maior manifestação contra o Governo no Dia da Inconfidência. (...) A maior faixa da manifestação continha o lema ...

\section{Jornal do Brasil}

. Oposição quer povo nas ruas contra FH

. No dia de Tiradentes, Itamar lidera protestos em Ouro Preto

. O governador de Minas, Itamar Franco, conseguiu unir a oposição em manifestação com cerca de 20 mil participantes contra o presidente Fernando Henrique Cardoso na Praça Tiradentes, a principal de Ouro Preto. Lideranças oposicionistas do país conclamaram o povo a ir às ruas para protestar contra Fernando Henrique.

. Oposição quer "povo na rua" contra FH

. Itamar leva cerca de 20 mil à praça no dia de Tiradentes

. Ouro Preto, MG - O governador de Minas, Itamar Franco (PMDB), conseguiu, ontem, na comemoração da Inconfidência Mineira, o que planejou durante dois meses. Cerca de 20 mil pessoas se aglomeraram na Praça Tiradentes e arredores para participar da maior manifestação realizada contra o presidente Fernando Henrique Cardoso (PSDB) e sua política econômica no segundo mandato. Na manifestação, organizada pelo governador mineiro, ... 
Folha de S. Paulo

. Itamar promove protesto e condecora MST

. Cerca de 20 mil pessoas, segundo a Polícia Militar, participaram ontem em Ouro Preto (MG) de uma manifestação contra o presidente Fernando Henrique Cardoso organizada pelo governo de Minas Gerais e com apoio das principais lideranças de esquerda.

. [A solenidade de entrega da Medalha da Inconfidência] neste ano ... foi planejada como uma cerimônia de protesto.

\section{Estado de S. Paulo}

. Itamar une esquerda em Ouro Preto

. Líderes dos opositores esquecem as divergências durante a comemoração do Dia de Tiradentes

. Ouro Preto - A comemoração do Dia de Tiradentes em Ouro Preto, ontem, transformou-se numa grande confraternização da esquerda brasileira.

. Este ano, ... Itamar transformou o evento num grande protesto contra o governo federal.

Recebido em: 28 de fevereiro de 2014.

Aceito em: 05 de junho de 2014. 